\title{
ON THE DIELECTRIC CONSTANTS OF NITRILES
}

\author{
BY HERMAN SCHLTNDT
}

\section{INTRODUCTION}

Recent investigations on the dissociative power of solvents and the electrical conductivity of non-aqueous solutions by Dutoit and Friderich, ${ }^{1}$ Kahlenberg and Lincoln ${ }^{2}$ and Lincoln, ${ }^{3}$ show that salts dissolved in acetonitrile, propionitrile and benzonitrile yield solutions that conduct well. For example, Dutoit and Friderich found the molecular conductivity at $25^{\circ} \mathrm{C}$ of silver nitrate dissolved in acetonitrile to be 54.5 at a dilution of $I$ g-mol in 8 liters, and $r$ I 8.3 at a dilution of $I$ g-mol in I 28 liters. The molecular conductivity of aqueous solutions of silver nitrate at $\mathrm{I} 8^{\circ} \mathrm{C}$, according to Kollirausch, ${ }^{5}$ is 88.6 at a dilution of $I \mathrm{~g}-\mathrm{mol}$ in Io liters, and 103.3 at a dilution of $I$ g-mol in 166.7 liters. It appears then that dilute solutions of silver nitrate in acetonitrile have a greater molecular conductivity than the corresponding aqueous solutions. The molecular conductivity of silver nitrate dissolved in benzonitrile, althongh lower than the conductivity of aqueons solutions, is still of considerable magnitude. For example, Lincoln ${ }^{5}$ found the molecular conductivity of silver nitrate dissolved in benzonitrile, at $25^{\circ} \mathrm{C}$, to be 5.18 and $16.3^{8}$ at the respective dilutions of I g-mol in 9.43 and 5 I. 96 liters.

1 Bull. Soc. Chim. (Paris) (3) r9, 321 (1898).

"Jour. Phys. Chem. 3, I2 (I899).

:Trans. Wis. Acad. Sciences, Arts and Letters, 12, 395. Also Jour. Phys. Chem. 3, 457 (IS99).

1. c.

"Wied. Ann, 26, 16I (1885).

i) $1 . \mathrm{c}$. 
Assuming the dissociation theory, the conclusion to be drawn from these results is, that acetonitrile and benzonitrile possess dissociating power in a high degree. On the basis of Nernst's and 'Thomson's argument that the greater the clielectric constant of solvents the greater is their dissociative power, the nitriles should have high values for their dielectric constants.

The dielectric constant of benzonitrile was measured by Drude and found to be 26.0 at $21^{\circ} \mathrm{C}$. Drude measured the dielectric constant of another nitrile, namely, benzy 1 cyanide, but his extensive investigation does not include any of the nitriles of the aliphatic series. In view of the great dissociating power of acetonitrile, it seemed of special interest to determine its dielectric constant and that of some of its homologues, and at the suggestion of Prof. Kahlenberg the investigation was undertaken.

Lincoln's $s^{r}$ measurements of the electrical conductivity of salts dissolved in pyridine show that it must be added to the list of solvents that possess marked dissociating power. Its dielectric constant was therefore also measured, and the value will be found appended to the results found for the nitriles investigated. The homolognes of pyridine, the substituted ammonias, together with other componnds, are now being investigated.

During the progress of his researches on non-aqueous solutions, Prof. Kahlenberg has collected a choice lot of preparations, which he kindly placed at my disposal. This greatly facilitated the experimental part of my work, and I desire to express to him my thanks for this favor.

\section{Method and Apparatus}

In measuring the dielectric constants the method devised and elaborated by Drude ${ }^{\mathrm{r}}$ was used. It is unnecessary for me

Zeit. phys. Chem. 13,53r (1893).

$\because$ Phil. Mlag. $36,320(1893)$.

"Zeit. phys. Chem. 23, 267 (1897).

+1 . c.

${ }^{5}$ 1. c. See also Wied. Ann. 55, 633 (1895); 58, I ; 59, 17 (1896); 60, $28,500(1897)$. 
to give a complete description of this method and of the details of the apparatus employed, since Drude has already done this. The reader is therefore simply referred to Drude's original article after reading which the additional remarks on the method that are contained in the paragraphs that now follow will be much better understood.

The apparatus used for these meastrements was a trifle larger than the one described by Drude. The wave-length of the electrical waves in the two parallel wires in air was about $84 \mathrm{~cm}$, as compared with $74 \mathrm{~cm}$ of the apparatus employed by Drude. A racuum tube containing hydrogen was used to determine the settings for maximum resonance. It served very well indeed for this purpose.

Of the two methods described by Drude, the first is the more accurate, but it necessitates the use of comparatively large quantities of substance, at least $200 \mathrm{cc}$, which, in most cases, were not available. Moreover, the poisonous nature of the nitriles made it desirable to work with small quantities which could be kept in a closed cell while under investigation. Drude's "second" method, although less accurate, was therefore chosen. This method enables one to operate with less than a cubic centimeter of solvent and gires results accurate to within 2 percent. In this method the substance to be measured is introduced into a small condenser, which is placed in the secondary circuit. The length of the secondary circuit is then adjusted for maximum resonance. The dielectric constant corresponding to the length noted is found from a calibration curve representing the results obtained in calibrating the apparatus for the particular condenser.

Three cells similar in form, but of different capacities, served as condensers. The apparatus was calibrated for each cell with the liquids recommended by Drude, namely; benzene, acetone, water, mixtures of benzene and acetone, and mixtures of acetone and water. Seventeen liquids whose dielectric constants range from 2.26 to 80.9 at $19^{\circ} \mathrm{C}$ were prepared. The benzene used for these calibrating solutions was Kallbaum's 
thiophene-free preparation, purified by crystallization. Its boiling-point was $79.2^{\circ} \mathrm{C}$ under $744.6 \mathrm{~mm}$, pressure. The acetone was Kahlbaum's preparation; it was prepared from the bisulphite compound. It boiled at $55.7^{\circ}$ under $746 \mathrm{~mm}$ of pressure. The water used had a specific conductivity of $3.6 \times 1^{-6}$.

In calibrating, the "zero" of the apparatus, obtained by placing a straight piece of copper wire in place of the cell, was frequently redetermined, as a change in the position of certain parts of the apparatus may produce a change of the "zero" point. This precantion was also taken whenerer solvents of unknown dielectric constant were under examination. As a check on any change in the capacity of the cells, the calibrating liquids whose dielectric constants were nearest in value to that found for the solvent under examination were introduced into the cell and the settings for maximum resonance determined. In this way any change in the position of the condenser plates could be readily detected. This procedure also gives all the necessary data for calculating the dielectric constant according to the formula developed by Drude, ${ }^{1}$

$$
\mathrm{D}=\mathrm{D}_{1}+\left(\mathrm{D}_{2}-\mathrm{D}_{1}\right) \frac{\cot \frac{2 \pi l}{\lambda}-\cot \frac{2 \pi l_{1}}{\lambda}}{\cot \frac{2 \pi l_{2}}{\lambda}-\cot \frac{2 \pi l_{1}}{\lambda}},
$$

in which $\lambda$ is the wave-length of the electric waves in air, $D$ is the dielectric constant sought, $l$ is the setting for maximum resonance when the cell contains the solvent whose dielectric constant is sought; $\mathrm{D}_{1}, l_{1}$, and $\mathrm{D}_{2}, l_{2}$, are the dielectric constants and settings of the calibrating solutions. In working with pyridine the dielectric constant was calculated by this formula, using $84 \mathrm{~cm}$ for $\lambda$. The value found was the same as the value obtained with the aid of the calibration curve.

From ro to 30 settings for maximum resonance were made for each solvent examined, and the arerage of these was the value used for obtaining the dielectric constant.

${ }^{1} 1$. c., p. 290. 
The methods of dehydrating and rectifying the varions solvents will be found under the head of each particular solvent in the statement of results given below.

A series of trial experiments was at first made with the apparatus in order to test it thoroughly. The dielectric constants of ethyl ether, chloroformi, ethyl benzoate, salicylic aldehyde, benzonitrile, and nitrobenzene were measured; and the results obtained agreed very well with those given by Drude. It is therefore, entirely superfluous to again report the numerical results obtained for these substances.

\section{Experimental Results}

The dielectric constants of the following aliphatic nitriles were measured; hydrocyanic acid, acetonitrile, propionitrile, butyronitrile, isopropyl cyanide, valeronitrile, isobutyl cyanide, and capronitrile. In the aromatic series benzonitrile, benzyl cyanide, and orthotolnonitrile were measured.

\section{Hydrocyanic Acid}

The sample of hydrocyanic acid used was prepared in the usual way by slowly adding a strong aqueous solution of potassium cyanide to sulphuric acid of sp. gr. 1.25 in a retort connected with a reflux condenser kept at $30^{\circ} \mathrm{C}$. The gas was then dried at $30^{\circ} \mathrm{C}$ by passing it through a series of three large U-tubes, kept at $30^{\circ} \mathrm{C}$, and containing fused calciun chloride. The gas was condensed in a tube provided with glass stop-cocks suspended in a bath at $O^{\circ}$. A colorless liquid was thus obtained, which left no residue upon evaporation. Some of the liquid was introduced into the cell adapted for the measurement of liquids having a high dielectric constant. The cell was securely stoppered and the measurements were made at $2 \mathrm{I}^{\circ} \mathrm{C}$. No appreciable absorption was observed, the position for maximum resonance being about as well defined as in the case of acetone. The dielectric constant found is higher than the dielectric constant of water. This necessitated an extrapolation of the calibration curve in order to get an approximate value. The dielectric constant found in this way is $95.0 \pm 3.5$. 
After this exceedingly high restilt had been obtained a second sample of hydrocyanic acid was prepared by redistilling the first sample from a water-bath kept at $30^{\circ} \mathrm{C}$. The gas was again passed through the drying tubes and condensed as before. Measurements with this sample gave the same readings for maximum resonance as in the first case. The temperature coefficient is negative; but it was not accurately determined.

The specific conductivity of the sample of hydrocyanic acid was not determined; but an investigation of the conductivity and other properties of salts dissolved in hydrocyanic acid is now in progress in this laboratory. Perhaps the specific conductivity will be low enough to permit the use of Nernst's apparatus for determining the dielectric constant. The improved form of Nernst's apparatus as described by 'Turner ${ }^{1}$ will soon be at hand, when an attempt to measure the dielectric constant of hydrocyanic acid by means of it will be made.

\section{Acetonitrite}

The sample of acetonitrile first measured was obtained by distilling a sample of Kahlbaum's make. Its boiling-point was very constant, being $80.9^{\circ} \mathrm{C}$ under a pressure of $745 \mathrm{~mm}$. The average of four determinations gave the value 36.5 for the dielectric constant at $2 I^{\circ} \mathrm{C}$.

A second sample, prepared by Prof. Kahlenberg from the Kahlbaum preparation by dehydrating it with phosphorus pentoxide and redistilling twice was measured. Its boiling-point was $80.7^{\circ}$ under $749 \mathrm{~mm}$ pressure. The measurements were made at $22^{\circ}$ and gave the same result as was obtained with the first sample.

A third sample, also furnished by Prof. Kahlenberg, was finally measured. This sample was twice dehydrated with larger quantities of phosphorts pentoxide than were used in the previous case, and was distilled from phosphorus pentoxide. It had a boiling-point of $80.2^{\circ} \mathrm{C}$ under a pressure of $736 \mathrm{~mm}$. The dielectric constant was calculated by the formula given above and found to be $36 . \mathrm{I}$ at $2 \mathrm{I}^{\circ}$.

${ }^{1}$ Zeit. phys. Chem. 35, 385 (1900). 


\section{Propionitrile}

This sample was Schuchardt's preparation. Its boilingpoint was $94.6^{\circ}$. The average of four determinations at different times gave the value 26.5 for the dielectric constant at $22^{\circ} \mathrm{C}$. The absorption was slight.

\section{Butyronitrile}

The sample tested was Schuchardt's preparation. It was redistilled from calcium chloride. Its boiling-point was 1 I $6.5^{\circ}$ to $\mathrm{I} 8^{\circ} \mathrm{C}$ under $74^{2} \mathrm{~mm}$ of pressure. The average of three different determinations was 20.3 at $2 \mathrm{I}^{\circ} \mathrm{C}$.

\section{Isopropyl Cyanide}

The sample was Schuchardt's preparation. It was dehydrated with calcium chloride and redistilled. Its boiling-point was $106^{\circ}-107^{\circ} \mathrm{C}$ under $744 \mathrm{~mm}$ pressure. The average of three determinations gave the value 20.4 for its dielectric constant at $24^{\circ} \mathrm{C}$.

\section{Valeronitrile (normal)}

The sample was obtained from Schuchardt. It was redistilled from calcinm chloride, and the portion which distilled between $\mathrm{I} 37^{\circ}-\mathrm{I} 39^{\circ} \mathrm{C}$, under $743 \mathrm{~mm}$ of pressure, was taken for the measurements. Its dielectric constant was found to be 17.4 at $2 I^{\circ} \mathrm{C}$.

\section{Isobutyl Cyanide}

The sample was Schuchardt's preparation; it was redistilled from calcinm chloride, and the portion distilling between $129^{\circ}-\mathrm{I} 30.5^{\circ} \mathrm{C}$ under a pressure of $742 \mathrm{~mm}$ was taken for the measurements. Its dielectric constant was found to be 17.95 at $22^{\circ} \mathrm{C}$.

\section{Capronitrile}

The sample used was obtained from Schuchardt. It was redistilled from calcium chloride, and the portion distilling between $\mathrm{I} 53^{\circ}-\mathrm{I} 54^{\circ} \mathrm{C}$, under $743 \mathrm{~mm}$ pressure, was taken for the measurements. Its dielectric constant was found to be 15.5 at 
$22^{\circ} \mathrm{C}$. The higher members of the series show a slight amount of absorption; but the maximum resonance is still well enough defined without increasing the intensity of the oscillations in the secondary circuit.

\section{Tolnonitrile (ortho)}

Schuchardt's preparation was redistilled from calcium chloride. A straw-colored distillate, boiling at $200^{\circ}-20 \mathrm{I}^{\circ} \mathrm{C}$, under a pressure of $7.33 \mathrm{~mm}$, was thus obtained. Its dielectric constant was found to be 18.5 at $23^{\circ} \mathrm{C}$. It showed slight absorption.

\section{Pyridine}

The first sample was Schuchardt's preparation. It was redistilled and found to boil from II $5.5^{\circ}$ to $117^{\circ}$ under $745 \mathrm{~mm}$ pressure. With this several measurements were made, the average of the results for the dielectric constant being I 2.35 at $2 \mathrm{I}^{\circ} \mathrm{C}$.

A second sample was furnished by Prof. Kahlenberg. Kahlbaum's best preparation was carefully purified by him according to the method given by Ladenburg. ${ }^{.}$The portion boiling at I $4^{\circ} \mathrm{C}$ under $744.6 \mathrm{~mm}$ of pressure, was used for the measurements. The dielectric constant was found to be 12.55 at $20^{\circ} \mathrm{C}$, a result which agrees well with the foregoing. The settings for maximum resonance were well defined.

\section{Quinoline}

Two samples of quinoline were measured. The first was obtained by redistilling Schuchardt's preparation marked, "Quinoline from Coal Tar." The portion which distilled at $232^{\circ} \mathrm{C}$ under $746 \mathrm{~mm}$ of pressure, was measured. Its dielectric constant was found to be 8.7 at $22^{\circ} \mathrm{C}$.

The second sample was a synthetic preparation, made by Messrs. Maxon and Thomas in this laboratory according to the method of Skranp. The boiling-point of the sample measured was $232^{\circ} \mathrm{C}$ under $746 \mathrm{~mm}$ of pressure. Its dielectric constant

'Liebig's Annalen, 247, I (1888). 
was found to be 8.9 at $20.5^{\circ} \mathrm{C}$. The agreement is close enough to fall within the linit of error. The absorption is slight. These values of the dielectric constant agree well with the result, 8.9, obtained by 'Tumer, ${ }^{\mathrm{T}}$ who worked with Nernst's apparatus.

The foregoing resnlts are summarized in the following table, the third columing giving the temperatures at which the dielectric constants were determined.

TABLF: I

\begin{tabular}{|c|c|c|c|}
\hline Solvent & Formula & $t^{\circ}$ & $\begin{array}{l}\text { Dielectric } \\
\text { constant } \\
\text { Air } 1\end{array}$ \\
\hline Hrdrocyanic acid & $\mathrm{HCX}$ & $2 \mathrm{I}$ & $9 \overline{0}$ \\
\hline Acetonitrile & $\mathrm{CH}_{3} \mathrm{CN}$ & $2 \mathrm{I}$ & $36 .+$ \\
\hline Propionitrile & $\mathrm{C}_{2} \mathrm{H}, \mathrm{CN}$ & 22 & 26.5 \\
\hline Butyronitrile & $\mathrm{C}_{\mathrm{H}} \mathrm{H}$ & $2 \mathrm{I}$ & 20.3 \\
\hline Isopropyl cyanide & $\ddot{C} H_{2}, \mathrm{CHCN}$ & 24 & 20.4 \\
\hline Valeronitrile $(n)$ & $\mathrm{C}_{1} \mathrm{H}_{1} \mathrm{CN}$ & $2 \mathrm{I}$ & $7 \cdot+4$ \\
\hline Isobutyl cyanicle & 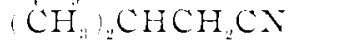 & 22 & 17.95 \\
\hline Capronitrile & $\left(\mathrm{CH}_{3}\right){ }_{2} \mathrm{CHCH}, \mathrm{CH} C \mathrm{CN}$ & 22 & 1.5 .5 \\
\hline Benzonitrile & $\mathrm{C}_{6} \mathrm{H}_{3} \mathrm{C} \mathrm{T}$ & $2 \mathrm{I}$ & 26.0 \\
\hline Benzyl cyanide" & $\mathrm{C}_{1 \mathrm{i}} \mathrm{H}_{3}^{\prime \prime} \mathrm{CH}_{2} \mathrm{CN}$ & $2 I$ & $1+\cdot 9$ \\
\hline Toluonitrile (ortho) & $\mathrm{C}_{i} \mathrm{H}_{t}<\mathrm{CH}$ & 2.3 & $18 .+$ \\
\hline Pyridine & $C_{i} \mathrm{H}_{0} \mathrm{~N}$ & $2 \mathrm{I}$ & 12.4 \\
\hline Quinoline' & $\mathrm{C}_{3} \mathrm{H}_{3} \mathrm{~N}$ & $2 \mathrm{I}$ & $S . B$ \\
\hline
\end{tabular}

The results obtained with the aliphatic nitriles are also presented graphically in Curve I. in the accompanying figure. The dielectric constants are plotted as ordinates, and the members of the homologons series are noted as abscissie, a definite distance being chosen for each addition of $\mathrm{CH}_{2}$.

Curre II. represents Drude's values for the dielectric constants of the alcohols, while Curre II $(a)$. presents approxinnately

\footnotetext{
1 Zeit. phys. Chen. 35, 385 (1900).

"Measured by 1)rude, who found 26.0 at $21^{\circ} \mathrm{C}$.

"Drude found 15.0 at $19^{\circ} \mathrm{C}$.

+ Turner found 8.9 with Nernst's apparatus.

51. c.
} 


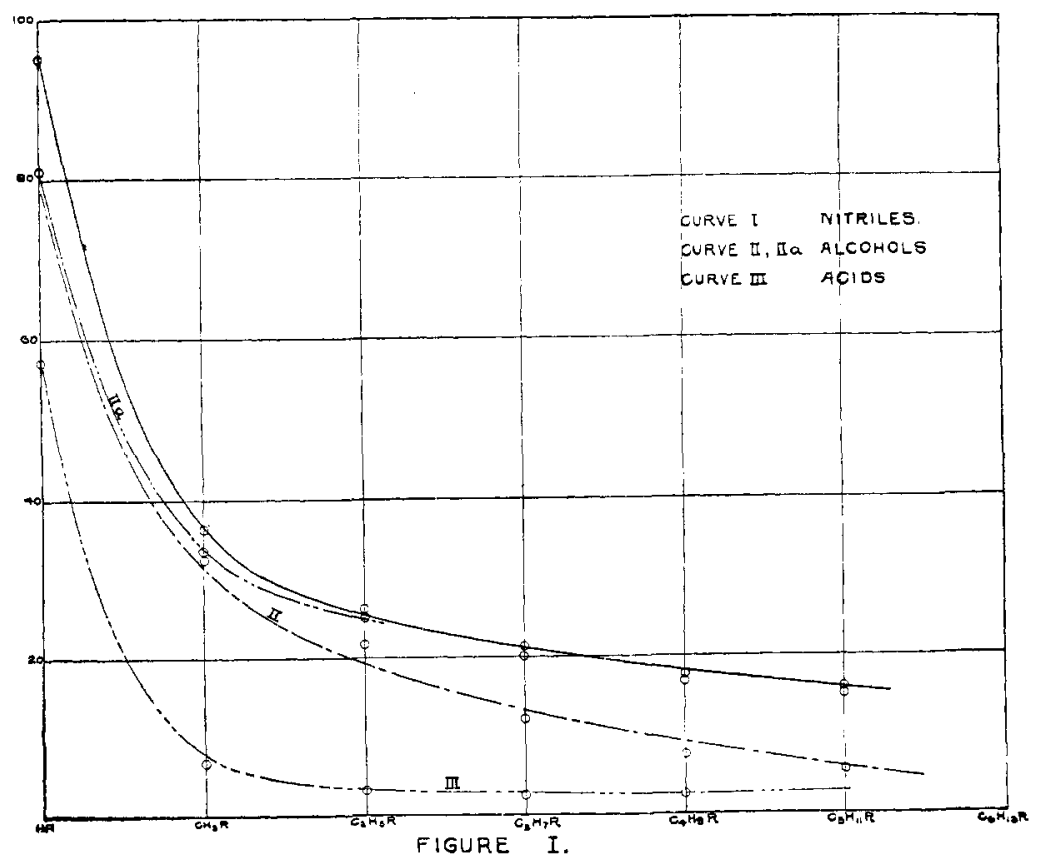

the values obtained by Thwing, ${ }^{1}$ Nernst, ${ }^{2}$ and Tereschin ${ }^{3}$ for the dielectric constants of the alcohols. Curve III. represents the values obtained by Drude for the dielectric constants of the fatty acids. Hence in Curve I., $\mathrm{R}$ represents the cyanogen group $(\mathrm{CN})$, in Curves II. and II ( $a)$, R represents the hydroxyl group $(\mathrm{OH})$, while in Curve III. it represents the carboxyl group $(\mathrm{COOH})$.

\section{Discussion of Results}

The high dielectric constant found for hydrocyanic acid is of special interest from a theoretical point of view, since by the Nernst-Thomson rule, that the greater the dielectric constant of a solvent, the greater is its dissociating power, hydrocyanic acid should show extraordinary dissociating power. The

${ }^{1}$ Zeit. phys. Chem. 14, 286 (1894).

Ibid., 14, 622 (1894).

"Wied. Ann. 36, 792 (1889). 
publication of the electrical conductivity measurements of salts dissolved in hydrocyanic acid, which are in progress in this laboratory, will therefore be awaited with interest.

The marked differences in the physical properties between the first two members of any homologons series are well exemplified here by the great differences in the dielectric constants between hydrocyanic acid and acetonitrile, water and methyl alcohol, formic acid and acetic acid. The curves show that an increase in the size of the molecule by the addition of carbon and hydrogen lowers the dielectric constant. This also holds for the aromatic nitriles and for pyridine and quinoline.

The isomeric nitriles examined have nearly the same dielectric constant, the iso-componnds showing a slightly higher value.

A comparison of the values of the dielectric constants of the alcohols and nitriles by means of Curves I. and II. shows that for high frequency oscillations the nitriles lave higher values for their dielectric constants throughont than the corresponding alcohols. For oscillations of low frequency the values for the dielectric constants of the higher members of the alcohol series are nearly the same as the values found for the corresponding nitriles with high frequency oscillations. Compare Curves II $(a)$ and I. Since the nitriles show but slight absorption, the dielectric constants when determined with Nernst's apparatus will probably agree closely with the values found with Drude's apparatus.

The researches of Dutoit and Friderich ${ }^{x}$ on the electrical conductivity of salts dissolved in acetonitrile, propionitrile, and butyronitrile show that the dissociating power decreases in the order in which the solvents are named. Their dielectric constants also decrease in the order named, thus supporting the NernstThomson rule. This relation between the dielectric constant and the electrical conductivity is illustrated by the following table. The molecular conductivity measurements are taken from the work of Dutoit and Friderich. In the table $\mu$ stands

'1. c. 
for the molecular conductivity at $25^{\circ} \mathrm{C}$, and $z^{\prime}$ the number of liters in which one gram-molecnle of silver nitrate is contained.

\section{TABLE: II}

\begin{tabular}{lc|c|c}
\multicolumn{1}{c}{ Solvent } & $r$ & $\mu_{r}$ & $\begin{array}{c}\text { Dielectric } \\
\text { constant } \\
\text { at } 21^{\circ} \mathrm{C}\end{array}$ \\
Acetonitrile & 64.0 & 103.7 & 36.4 \\
Propionitrile & 63.7 & 46.0 & 26.5 \\
Butyronitrile & 75.6 & 25.4 & 20.3
\end{tabular}

Propionitrile and benzonitrile have about the same dielectric constant; but the molecular conductivities of silver nitrate dissolved in these nitriles are quite different, as a comparison of the rcsults in the following table shows. The molecular conductivities for silver nitrate in benzonitrile are taken from Lincoln's ${ }^{x}$ work. The molecular conductivities for silver nitrate ate taken from the work of Dutoit and Friderich. ${ }^{2}$

\section{TABLE III}

\begin{tabular}{|c|c|c|c|}
\hline \multicolumn{2}{|c|}{ Benzonitrile } & \multicolumn{2}{|c|}{ Propionitrile } \\
\hline . & & $-\ldots$. & $\begin{array}{lll}\cdots & -\ldots & -\ldots\end{array}$ \\
\hline$a^{\prime}$ & $\mu_{\pi^{\prime}}$ at $25^{\circ} \mathrm{C}$ & $z$ & $\mu_{\text {, at }} 25^{\circ} \mathrm{C}$. \\
\hline 24.06 & 7.66 & 32.0 & 34.9 \\
\hline 58.98 & II. IY & 63.7 & 46.0 \\
\hline $83.9^{2}$ & $13.4 \mathrm{I}$ & & \\
\hline
\end{tabular}

The molecular conductivities of silver nitrate dissolved in pyridine and in butyronitrile furnish another interesting comparison.

\section{TABLE, IV}

Solvent

Butyronitrile"

Pyridine

$$
\begin{array}{r}
75.6 \\
150.7 \\
60.9 \\
140.7
\end{array}
$$

11. c., p. 422.

'1. c., p. 330.

"Dutoit and Friderich. 1. c., p. 331.

${ }^{4}$ Lincoltr. 1. c., p. 423.
Dielectric constant

20.3

I 2.4

\begin{tabular}{l|l}
25.4 & 20.3 \\
32.1 & \\
30.17 & I 2.4 \\
36.21 &
\end{tabular}


While Table II. shows that the Nernst-Thomson rule holds for the three members of the same lomologous series, Table III. demonstrates that chemically analogous substances having about the same dielectric constants may nevertheless yield solutions (containing the sanne solnte) with very different electrical conductivities. Table IV. shows conchusively that a pyridine solution of silver nitrate conducts better than a corresponding one in butyronitrile, notwithstanding the fact that the dielectric constant of pyridine is only 6 r percent of that of butyronitrile. We have here then a striking case in which the Nernst-Thomson rule does not hold. It is well in this connection to bear in mind the fact that Coodwin and Thompsont have found that liquid ammonia is also a striking exception to the Nernst-Thomson rn1e.

It is evident from the above results that the Nernst-Thomson rule holds at best only for the nembers of the same homologous series. It is also clear that the dielectric constant of a solvent is not the sole factor determining whether solutions in that solvent will conduct electricity or not.

I am indebted to Prof. Kahlenberg for his suggestions and assistance, and I take this means of acknowledging the same.

Laboratory of Physical Chemistry,

linizersity of Wisconsin,

Madison, Wis.

Jan.30, 190r.

'Phys. Review, 8, 4.3 (1899). 